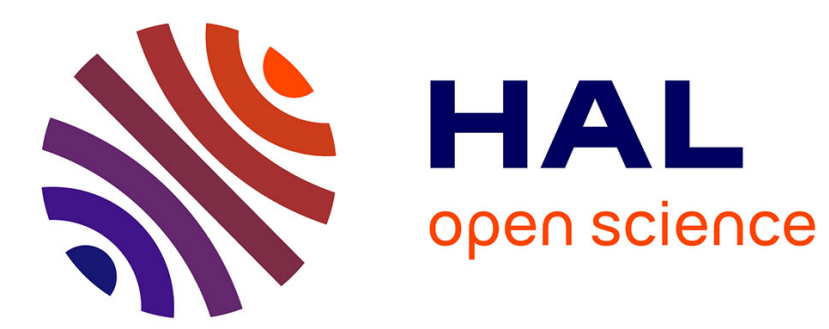

\title{
The synchrotron laboratory of Catalonia
}

R. Pascual

\section{- To cite this version:}

R. Pascual. The synchrotron laboratory of Catalonia. Journal de Physique IV Proceedings, 1994, 04 (C9), pp.C9-337-C9-340. 10.1051/jp4:1994957 . jpa-00253520

\section{HAL Id: jpa-00253520 https://hal.science/jpa-00253520}

Submitted on 1 Jan 1994

HAL is a multi-disciplinary open access archive for the deposit and dissemination of scientific research documents, whether they are published or not. The documents may come from teaching and research institutions in France or abroad, or from public or private research centers.
L'archive ouverte pluridisciplinaire HAL, est destinée au dépôt et à la diffusion de documents scientifiques de niveau recherche, publiés ou non, émanant des établissements d'enseignement et de recherche français ou étrangers, des laboratoires publics ou privés. 


\title{
The synchrotron laboratory of Catalonia
}

\author{
R. Pascual
}

Department of Physics and Institut de Física d'Altes Energies, Universitat Autònoma de Barcelona, 08193 Bellaterra, Spain

\begin{abstract}
The project of a Synchrotron Laboratory in Barcelona is presented. Its feasibility was analized by a special committee created in July 1992 and was aproved by the Regional Government of Catalonia in February 1993 in its Research Plan for 1993-1996. Since then a Steering Committee and an Advisory Committee have been operating and the firsts steps have been taken: the agreement for collaboration with the Spanish Administration, the choice of a possible site with the appropriated geotechnical characteristics and the search for provisional headquarters. Since experience in the field of accelerator sciences and technologies is very scarce in Spain, we are starting a training program for young graduate students and recent Ph.D. and a program dedicated to local industries.
\end{abstract}

\section{INTRODUCTION}

In the last years Spain has made a big effort of participation in European facilities related to accelerators, such as CERN and ESRF; also some efforts have been made in order to have a beam line in LURE. The number of members of the high energy physics community working in connection to CERN is around one hundred and those involved in the use of synchrotron ligth are around 70 (at the $\mathrm{Ph} \mathrm{D}$ level). These figures are significative, but they are a bit low compared to the corresponding ones in other European countries, even taking into account the present scientific level of Spain.

The only existing accelerators at national level are a few commercial ones existing in hospitals and devoted to medical assistence. This is the main reason why there are almost no Spanish specialists in accelerator physics and related technologies and why the presence of Spanish personnel is so low in the European laboratories.

It is for this reason that in the last few years there have been some intents to establish a domestic facility in order to start the training of people and to help Spanish companies in adquiring the technologies related to particle accelerators. The possibility of being the site of a tau charm factory, with a syncrhotron radiation facility in its second phase, was considered some time ago. When that project was withdrawn, the possibility of a synchrotron facility was considered by a group of people under the iniciative of the Regional Government of Catalonia. That group was formed by some experts in the field, some representatives of the Catalan administration and responsibles of the Catalan universities and 
research centers. After some consultations with synchrotron radiation users and high energy physicists, a feasibility study ${ }^{1}$ was presented to the regional government in December 1992 and it was included in the Research Plan of Catalonia 1993-1996 2.

While the decision to build the new laboratory is an initiative of the regional government (the Generalitat de Catalunya) the intention is to serve not only Catalan users, but also users of the rest of Spain and probably of other neighbouring countries, and to facilitate access to scientists from other countries wishing to carry out quality research. Its construction will need the indispensable cooperation of specialists from CERN and ESRF, and also from other laboratories, primarily in Europe, to take care of the training of staff, and in the form of the temporary or extended secondment of key people. In the following sections we present the main conclusions and proposals of that study as well as the present status of the project.

\section{THE SYNCHROTRON LABORATORY}

The idea is to construct a large (for the Spanish standards) research laboratory based on an electron synchrotron for producing synchrotron light, as well as to serve other scientific programmes related to high-energy physics and other activities requiring an electron beam. The aim is for such a facility to be created in the most autonomous possible manner, relying to the full on our own human and technological resources. At the same time, it is also intended that this facility be recognized internationally.

The objectives to be pursued with this proposed new laboratory, apart from the research which will use both the synchrotron's electron beam and the synchrotron light itself, are personnel training and technological development. With regard to training, while available human resources will certainly be used, the aim is to create a community of scientists and technicians - as yet virtually non-existent with specialist expertise in the area of accelerators and instrumentation in general. With regard to technological development, it is hoped that a large part of the new facility will be constructed using technologies provided by Catalan and Spanish companies, and to this end the envisaged implementation schedule allows these companies to have enough time for the acquisition of new processes which they do not have at their disposal yet. Once the facility will be operational, the possibility of access to synchrotron light should encourage a number of companies to consider using it in their own research work. In addition to these goals, the new facility should allow us to optimize our participation and contribution to both CERN and ESRF, and to obtain long-term benefits in know-how and technology transfer.

Therefore it becomes necessary to think in terms of an electron storage ring of $2.5 \mathrm{GeV}$ equipped with conventional dipolar magnets, not excessively intense, that could be produced by local firms; for example, 1.2 T. This implies a critical energy (defined as the one for which half of the power corresponds to lower energies, and the other half to higher energies) around $5 \mathrm{keV}$ : thus the intensity which would be obtained in the region of $15 \mathrm{keV}$ would still be acceptable. The current would have to be around 200 or $300 \mathrm{~mA}$. If the lattice of magnets were what is known as "double bent achromat", the length of each superperiod would be around 16-17 m; allowing for straight sections of about $4 \mathrm{~m}$. If we envisage 12 superperiods, we arrive at a ring length of around $250 \mathrm{~m}$, in other words, a radius of about $40 \mathrm{~m}$.

1 The Synchrotron Laboratory of Catalonia: Feasibility Study; J. Bordas, E. Fernández, S. Ferrer, A. Mariné, C. Miravitlles, P. Miró, A. Oliva, X. Ortega, J. Pascual, R. Pascual and R. Tarrach; Barcelona, January 1993.

2 Pla de Recerca de Catalunya 1993-1996, Comissió Interdepartamental de Recerca i Innovació

Tecnològica, Generalitat de Catalunya, May 1993. 
This would allow in the long term to have at our disposal 12 beam lines in the dipoles and 9 insertion devices since two of the rectilinear stretches are occupied by radiofrequency cavities and one by the injection system. During the first phase, the one we are concerned with in this study, we should be able to construct a few lines of dipoles and of insertion devices. The characteristics of the beam lines will be decided in the next months on the basis of users' needs. The majority of the lines will be of the conventional type, but it will also be necessary to provide a small number of very specialized lines with greater capabilities, probably with superconducting magnets.

The electrons are to be supplied by an injection system composed of a linear accelerator and a synchrotron (booster). Both these devices can be fitted inside the main ring. We have in mind here a 200 $\mathrm{MeV}$ linac, which can be bought ready-assembled. The booster will have to accelerate the electrons up to $2.5 \mathrm{GeV}$ in order to refill the ring when the intensity of the current has diminished, which should happen once a day. Another option is that the booster would only reach an energy level of $1 \mathrm{GeV}$, which would make it cheaper. In this case, when the ring had to be refilled, it would be used as a synchrotron to accelerate the electrons up to $2.5 \mathrm{GeV}$ and this would entail modifications to the machine parameters once a day. The saving which this solution represents would seem to be outweighed by the resulting inconveniences and the danger that many hours of running time might be lost.

With regard to horizontal emittance, a lattice such as the one described would give a theoretical emittance of around $7 \mathrm{~nm}$ rad and a working emittance between 15 and $30 \mathrm{~nm}$ rad, which appears to be reasonable, and can if necessary be upgraded at a later stage.

The selection of these parameters has been determined by various factors: a) it appears that the experimental techniques currently undergoing the greatest development are those using photons at the proposed energies; b) the technologies required are fairly conventional, and they are therefore within the reach of local companies; $c$ ) the intention is that the facility should have a long operational and competitive life. With these characteristics the facility is intended to be a complement to the ESRF, which will make available a higher energy and brilliance.

The approximate schedule for the facility's construction and coming into full operational readiness is around 10 years, with the possibility that some research programmes might be able to start a couple of years earlier. The length of this time-scale is imposed by the necessity for a preliminary training of a number of specialists in certain specific techniques and to allow the companies to acquire the necessary technologies.

It is intended to endow the laboratory with some characteristic making it attractive to research groups from other countries, thus ensuring that it is a genuinely international facility. The location of the site, which should comprise between 6 and 8 hectares to allow for future expansion, is expected to be in the Vallès region, on land provided by the Universitat Autònoma de Barcelona. The area's excellent communications indicate that this is an optimum location, taking also into account the synergies represented by the proximity of the Catalan universities and other public and private institutions in the Vallès region.

For an efficient management of the laboratory, it is essential that it should enjoy a certain level of operational autonomy. Therefore, it is proposed that it be established by statute as a public company subject to civil law. Its organizational structure will be analyzed to ensure that, while certainly having points of similarity with equivalent facilities in other countries, it would be operative in the context of our legislative environment.

With regard to the budget, it has been calculated around 11,000 million pesetas of investment, spread over the 9 or 10 years needed for construction. It is considered that a large part of this initial 
expenditure could be met from ERDF funds, which have already been used to help other advancedtechnology facilities in the Vallès. The scientific, technological and entrepreneurial implications of a facility such as the one here proposed make it ideally suited to accord with objective no. 2 of the terms governing structural funds (concerned with regions affected by industrial decline), which applies to the Vallès area. It should be borne in mind that within the STRIDE initiative one of the priority aims is the promotion of relations between research and industry. The running costs of the facility are estimated at a maximum of 2,000 million pesetas per annum, including the research costs of the laboratory.

\section{PRESENT STATUS}

A Steering Committee for the laboratory was created at the beginning of 1993. The current Chairman is Dr. Joan Maj6, former Minister of Industry of the Spanish Government (1985-86) and Conseiller Hors Classe of the European Union (1989-1993). This Committee has representatives of the different departments of the Catalan Administration ${ }^{3}$. At the same time it was created an Advisory Committe chaired by Prof. Manuel Cardona ${ }^{4}$, from the Max Planck Institute, Stuttgart.

At present negotiations with representatives of the Spanish Administration are continuing. This represents a delay with respect to the first schedule; this delay is due to internal political reasons and also to the bad situation of the global economy. Even if the there is a willingness at the highest levels of the Spanish Government to participate in the synchrotron project, it is not easy to find the exact way of implementing that participation, and it is not the will of the regional government to pursue the project without that Spanish participation. During the last weeks there has been an increase of the efforts to find an agreement, with actions such as a meeting of the Spanish Minister of Education and Science with the Catalan Minister of Universities and Research, and meetings at other levels are scheduled. In the most pesimistic case one expects to arrive to an agreement before summer.

Nevertheless, other activities are going on. The Catalan Administration selected nine students to start the training in accelerator techniques the 1st of January of 1994. Some of them were just recent graduates and some were recent doctors from several fields; some of them had some experience, since they had spent some time at ESRF, CERN or INFN. They attended the Accelerator School organized by a Consortium of European Universities and CERN in Archamps, from the midle of January to Easter. After Easter they will continue their training in Barcelona and in some other laboratories.

After the decision by the Social Council of the Autonomous University of Barcelona of supplying the site for the laboratory, a geotechnical survey has been contracted to a private company for a total cost of 36 million Pts. Another independent company has been selected to follow the survey and to make the final reports. The survey started at mid January and at present the first hole has reached 50 meters of depth. In a few months a first idea about the goodness of the site will be available.

Conversations are under way for renting $945 \mathrm{~m}^{2}$ for the laboratory offices and $250 \mathrm{~m}^{2}$ in the ground floor for the laboratories. This will be the temporary site of the laboratory until 1996. These belong to a company participated by the University and are in a new building in the campus, near the proposed final site of the laboratory.

\footnotetext{
${ }^{3}$ Its members are Ramon Pascual, Josep Grifoll, Joan Albagés, Pere Miró, Antoni Gurguí i Antoni Salamero.

${ }^{4}$ Its members are Eberhard Jaeschke (BESSY II, Berlin), Gerhard Materlik (HASYLAB, Hamburg), Yves Petroff (ESRF, Grenoble), Gunther Plass (CERN, Geneva), Juan M. Rojo (UCM, Madrid), Sergio Tazzari (Frascati, Roma), D.J. Thompson ( SERC, Daresbury) and Felix Yndurain (UAM, Madrid).
} 